\title{
Matrine exerts inhibitory effects in melanoma through the regulation of miR-19b-3p/PTEN
}

\author{
YAN PING WEI $^{1}$, XIANG HUA WANG $^{1}$, GANG LIU $^{1}$, JIN FENG ZHANG ${ }^{1}$, YONG XIAN YANG ${ }^{1}$, \\ JUAN ZHANG $^{1}$, XIAO LI SONG ${ }^{1}$, ZHONG DONG LI ${ }^{2}$ and LIN DONG ZHAO ${ }^{1}$
}

\author{
Departments of ${ }^{1}$ Dermatology and ${ }^{2}$ Hematology, The People's Hospital of Jiaozuo City, Jiaozuo, Henan 454000, P.R. China
}

Received January 8, 2018; Accepted April 30, 2018

DOI: $10.3892 /$ ijo.2018.4414

\begin{abstract}
Matrine, one of the main alkaloid components extracted from the traditional Chinese herb, Sophora flavescens Ait, has various pharmacological effects, and has been reported to exert antitumor activity in melanoma. In the current study, the molecular mechanisms underlying the inhibitory effects of matrine were investigated in melanoma cell line. It was initially confirmed that matrine inhibited proliferation, invasion and induced apoptosis in human A375 and SK-MEL-2 melanoma cell lines in vitro. Subsequently, reverse transcription-quantitative polymerase chain reaction (RT-qPCR) analysis demonstrated that the expression of microRNA (miR)-19b-3p was significantly increased in melanoma cells and was downregulated by treatment with matrine. Furthermore, downregulated miR-19b-3p exerted effects similar to $500 \mu \mathrm{g} / \mathrm{ml}$ matrine on cell proliferation, invasion and apoptosis. Phosphatase and tensin homolog (PTEN) mRNA was identified as a direct target of miR-19b-3p through bioinformatics analysis and a dual-luciferase reporter assay. Additionally, western blotting and RT-qPCR analysis demonstrated that the expression of PTEN protein and mRNA were increased by the treatment with matrine. Furthermore, silencing of PTEN expression reversed the effects of matrine and miR-19b-3p downregulation in A375 and SK-MEL-2 cells. Taken together, the results indicated that matrine may suppress cell proliferation and invasion and induce cell apoptosis partially via miR-19b-3p targeting of PTEN.
\end{abstract}

\section{Introduction}

Melanoma is a type of skin cancer caused by excessive hyperplasia of abnormal melanocytes. It is prone to relapse and metastasis, which makes it one of the leading causes of

Correspondence to: Mrs. Yan Ping Wei, Department of Dermatology, The People's Hospital of Jiaozuo City, 267 Jiefang Road, Jiaozuo, Henan 454000, P.R. China

E-mail: weiyanping1977716@126.com

Key words: melanoma, matrine, microRNA-19b-3p, phosphatase and tensin homolog, proliferation, invasion, apoptosis mortality among skin cancers (1). Recently, molecular targeted therapy has provided potential for intervention at a molecular level by modulating certain signaling pathways as a form of cancer treatment and offers the promise of novel treatments for melanoma through the associated in-depth analyses of signal transduction pathways. Several antagonistic drugs directed against melanoma have been put into clinical use (2-4). However, melanoma has developed into one of the fastest growing cancers in terms of incidence rate in recent years, with an annual rate of growth of 3-5\% $(5,6)$. As a result, identifying novel targets for the treatment of melanoma remains an urgent need at this stage.

Matrine is a major alkaloid extracted from Sophora flavescens (7) and is also naturally present in subprostrate Sophora (8) and Sophora alopecuroides (9). Matrine exhibits several pharmacological effects, including anti-arrhythmia (10), antiinflammation (11), and antitumor activities (12-15). The wide spread use of matrine is attributed to its low toxicity. The anticancer properties of matrine are associated with its ability to inhibit proliferation and invasion and induce apoptosis in tumor cell lines through a vast number of pathways $(13,16,17)$. However, in the case of melanoma, the matrine mechanism of action has not been clarified.

MicroRNAs (miRNAs/miRs) are considered to have important roles in tumors. It has recently been reported that matrine alters miRNA expression profiles in SGC-7901 human gastric cancer cells, providing a novel and promising approach to identify the mechanisms of action of matrine (18). In this study, an miRNA microarray was used to screen relative miRNA levels of SGC-7901 human gastric cancer cells following matrine treatment (18). Among the results, miR-19b was of particular interest. Compared with the untreated cells, miR-19b was significantly downregulated in SGC-7901 cells following matrine treatment. Another study reported that miR-19b promoted breast cancer metastasis by targeting myosin regulatory light chain interacting protein and associated cell adhesion molecules (19). Additionally, it has been reported that miR-19b-3p may promote colon cancer proliferation and oxaliplatin-based chemoresistance by targeting SMAD4 (20). Notably, in melanoma, miR-19b was reported to be a novel upstream effector of telomerase reverse transcriptase transcription via direct targeting of mRNA encoding pituitary homeobox 1 (21). Additionally, miR-19b was downregulated following matrine treatment in gastric cancer cell lines (18). 
Thus, in the present study, it was aimed to determine whether matrine regulates miR-19b in melanoma via certain pathways to alter the proliferation, invasion and apoptosis of melanoma cells.

\section{Materials and methods}

Cell lines and cell culture. A375 and SK-MEL-2 cells have been widely used in melanoma research in vitro $(22,23)$. The two cell lines were purchased from the cell bank of the Chinese Academy of Sciences (Shanghai, China). Normal human epidermal melanocytes (NHEMs) and three melanoma cell lines (SK-MEL-1, A875 and M21) were purchased from Zhong Qiao Xin Zhou Biotechnology Co., Ltd. (Shanghai, China). The cell lines were cultured in a humidified atmosphere of $5 \% \mathrm{CO}_{2}$, with the temperature set to $37^{\circ} \mathrm{C}$. Cells were cultured in Dulbecco's modified Eagle's medium (DMEM; Gibco; Thermo Fisher Scientific, Inc., Waltham, MA, USA) containing 10\% fetal bovine serum (FBS; Thermo Fisher Scientific, Inc.), $100 \mathrm{U} / \mathrm{ml}$ penicillin and $100 \mu \mathrm{g} / \mathrm{ml}$ streptomycin.

Reagents. Matrine ( $>98 \%$ purity) was purchased from Rochen Pharma Co., Ltd. (Shanghai, China) and dissolved in DMEM medium to make a $10 \mathrm{mg} / \mathrm{ml}$ stock solution and stored at $-20^{\circ} \mathrm{C}$ in the dark.

Cell treatment. A375 and SK-MEL-2 cells were exposed to different treatments and divided into several groups according to the experimental design. A375 and SK-MEL-2 cells were directly treated with 0,250 and $500 \mu \mathrm{g} / \mathrm{ml}$ matrine; additionally, the two cells were transfected with anti-miR-19b-3p (cat. no. B03001; Shanghai GenePharma Co., Ltd., Shanghai, China), of miR-19b-3p mimics (cat. no. B01001) or small interfering RNA (si) targeting phosphatase and tensin homolog (PTEN; cat. no. A01001; Shanghai GenePharma Co., Ltd.) or co-transfected with si-PTEN and the first two miRNAs. In the experiments, anti-miR-control (cat. no. B04003) was used as a control for anti-miR-19b-3p mimics, miR-control (cat. no. B04001) (both from Shanghai GenePharma Co., Ltd.) was used as a control for miR-19b-3p mimics, and the blank group and scramble si-PTEN group was used as a control for si-PTEN. The blank group was untransfected cells. For transfection, A375 and SK-MEL-2 cells were cultured in the complete medium without antibiotics for $>24 \mathrm{~h}$ and washed with 1X PBS (pH 7.4) and then transiently transfected with the appropriate constructs $(20$ pmol for 24-well plate or 100 pmol for 6-well plate) using Lipofectamine ${ }^{\circledR} 2000$ (Invitrogen; Thermo Fisher Scientific, Inc.) according to the manufacturers' instructions. The sequences were as follows: Anti-miR-19b-3p, 5'-UCAGUU UUGCAUGGAUUUGCACA-3'; miR-19b-3p mimic, 5'-UGU GCAAAUCCAUGCAAAACUGA-3' and 5'-AGUUUUGCAU GGAUUUGCACAAG-3'; si-PTEN, 5'-AGAUGUUAGUGACA AUGAACC-3' and 5'-GGUUCAUUGUCACUAACAUCU-3' .

Cell counting kit-8 (CCK-8) assay. The CCK-8 assay is a method for evaluating the proliferation of A375 and SK-MEL-2 cells in vitro. The cells into several groups as described above. Following treatment or transfection for 24-72 h, $10 \mu \mathrm{l}$ CCK-8 reagent was added to the medium with $90 \mu \mathrm{l}$ DMEM and FBS.
The cells were incubated for $4 \mathrm{~h}$. The absorbance at $450 \mathrm{~nm}$ [optical density (OD)450] was measured using a microplate reader (Bio-Rad Laboratories, Inc., Hercules, CA, USA) to estimate viable cell numbers.

Transwell assay. A Transwell assay was performed to analyze cell invasion. For this assay, $5 \times 10^{5} \mathrm{cells} / \mathrm{ml}$ A375 and SK-MEL-2 cells were cultured in the upper chamber of a 24-well Transwell Permeable Support with $100 \mu \mathrm{l}$ serum-free DMEM; whereas, the lower chamber was filled with $400 \mu 1$ medium containing $10 \%$ FBS. Subsequently, the plate was incubated for $48 \mathrm{~h}$. Subsequently, cells in the upper chamber were then removed with a clean cotton swab, and cells that had migrated to the lower chamber through Matrigel were fixed with $99.5 \%$ methanol at room temperature for $30 \mathrm{~min}$. To determine the number of cells via microscopy, $0.1 \%$ crystal violet staining for $10 \mathrm{~min}$ at room temperature was performed. Cells were counted in three randomly selected fields under an inverted light microscope and each experiment was repeated in triplicate independently.

Flow cytometry. In normal cells, phosphatidylserine (PS) is only distributed inside of the membrane lipid bilayer. When the earliest steps of apoptosis occur, PS translocates to the outside of the membrane, and can bind with the calcium-dependent phospholipid-binding protein Annexin V. Thus, Annexin V binding is a sensitive marker for detecting early cell apoptosis. Propidium iodide (PI) is a nucleic acid dye. It is unable to penetrate the whole cell membrane of intact cells, while it is able to penetrate and stain late apoptotic and dead cells due to the increased permeability of the cell membrane. In the current study, Annexin V-fluorescein isothiocyanate (FITC)/PI was applied to detect the apoptosis of A375 and SK-MEL-2 cells via flow cytometry according to the instructions of the FITC Annexin V Apoptosis Detection Kit I (BestBio Science, Shanghai, China). For this assay, $5 \times 10^{5}$ cells $/ \mathrm{ml}$ were cultured following treatment of matrine for $48 \mathrm{~h}$ or transfection with miRs and siRNA for $24 \mathrm{~h}$. A total of $1 \times 10^{4}$ cells were harvested during the flow cytometry and each experiment was performed in triplicate.

Caspase-3/7 activity detection. Caspase-3/7 activity detection is another method to evaluate apoptosis. According to the instructions of the Caspase-Glo ${ }^{\circledR}$ 3/7 assay (Promega Corporation, Madison, WI, USA), $4 \times 10^{4}$ of cells were seeded in 96-well plates and cultured with matrine $(0,250$ and $500 \mu \mathrm{g} / \mathrm{ml})$ for 24 h. Caspase-Glo ${ }^{\circledR}$ 3/7 buffer and substrate were thoroughly dissolved to form the Caspase-Glo ${ }^{\circledR} 3 / 7$ reagent. The wells containing matrine, cell culture medium and Caspase-Glo ${ }^{\circledR}$ 3/7 reagent without cells were used as a blank group. The wells containing Caspase-Glo ${ }^{\circledR} 3 / 7$ reagent and cells without matrine treatment in culture medium were used as negative control group. The wells containing Caspase-Glo ${ }^{\circledR} 3 / 7$ reagent and cells under treatment of matrine in cell culture medium were used as the experimental groups. After incubation for $3 \mathrm{~h}$ at $37^{\circ} \mathrm{C}$, the luminescence of each group was measured in a luminometer plate reader at an excitation wavelength of $490 \mathrm{~nm}$ and an emission wavelength of $530 \mathrm{~nm}$.

RNA isolation and reverse transcription-quantitative polymerase chain reaction ( $R T-q P C R)$. Total RNA exaction from 
A375 and SK-MEL-2 cells following transfection or treatment for $24 \mathrm{~h}$ was performed with an E.Z.N.A. Total RNA Kit I (Omega Bio-Tek, Inc., Norcross, GA, USA). RNA was reverse transcribed to cDNA using a First Strand cDNA Synthesis Kit (Thermo Fisher Scientific, Inc.) according to the manufacturer's instructions. For the detection of miR-19b-3p, RT-qPCR was performed with a high-specificity miR-19b-3p RT-qPCR Detection Kit and ABI Power SYBR Green PCR Master Mix (both from Applied Biosystems; Thermo Fisher Scientific, Inc.), with U6 small nuclear RNA used as the endogenous control for normalization. For detection of PTEN mRNA, qPCR was performed with an ABI 7500 Fast System (Applied Biosystems; Thermo Fisher Scientific, Inc.), with GAPDH for PTEN normalization used as the endogenous control. The relative expression of miR-19b-3p and PTEN mRNA were calculated using the $2^{-\Delta \Delta \mathrm{Cq}}$ method (21).

The primers for miR-19b-3p were as follows: RT primer, 5'-GTCGTATCCAGTGCAGGGTCCGAGGTATTCGCACTG GATACGACACACGTT-3'; forward, 5'-TCCGAAGTCAAA ACGTACCTA-3' and reverse, 5'-GTGCAGGGTCCGAGGT-3'. The primers for U6 were as follows: RT primer, 5'-GTCGTA TCCAGTGCAGGGTCCGAGGTATTCGCACTGGATACGA CAAAATA-3'; forward, 5'-TCCGATCGTGAAGCGTTC-3' and reverse, 5'-GTGCAGGGTCCGAGGT-3'. The primers for PTEN mRNA were as follows: forward, 5-CAAGATGATGTT TGAAACTATTCCAATG-3 and reverse, 5'-5-CCTTTAGCT GGCAGACCACAA-3'. The primers for GAPDH were as follows: forward, 5'-ACAACAGCCTCAAGATCATCAGC-3' and reverse, 5'-CACGCCACAGTTTCCCGGAG-3'. The RT-PCR reaction conditions were $16^{\circ} \mathrm{C}$ for $10 \mathrm{~min}, 42^{\circ} \mathrm{C}$ for $60 \mathrm{~min}, 85^{\circ} \mathrm{C}$ for $5 \mathrm{~min}$, and paused at $16^{\circ} \mathrm{C}$. The qPCR reaction conditions were $95^{\circ} \mathrm{C}$ for $3 \mathrm{~min}, 40$ cycles at $95^{\circ} \mathrm{C}$ for $30 \mathrm{sec}$ and $60^{\circ} \mathrm{C}$ for $40 \mathrm{sec}$, melting curve $\left(60^{\circ} \mathrm{C}\right.$ for $60 \mathrm{sec} ; 95^{\circ} \mathrm{C}$ for $\left.15 \mathrm{sec}\right)$.

Western blotting. Total protein from A375 and SK-MEL-2 cells $\left(5 \times 10^{6}\right.$ cells) after transfection or treatment for $24 \mathrm{~h}$ was homogenized in lysis buffer and was quantified. The lysis buffer was a mix of phenylmethylsulfonyl fluoride and radioimmunoprecipitation assay buffer (Beyotime Institute of Biotechnology, Haimen, China) according to the ratio of 1:99. A bicinchoninic acid protein assay kit (Beyotime Institute of Biotechnology) was used to quantify the total protein. In the process of western blotting, the total protein $(30 \mu \mathrm{g})$ was separated by $10 \%$ SDS-PAGE and transferred onto a nitrocellulose membrane at $90 \mathrm{~V}$ for $80 \mathrm{~min}$. Tris-buffered saline (TBS; 1X) and $20 \%$ Tween-20 $(5 \mathrm{ml})$ were mixed to produce TBST. Following washing in 1X TBST for $3 \mathrm{~min}$, the membrane was blocked in $3 \%$ FBS for $1 \mathrm{~h}$ at room temperature and probed with the primary antibody (mouse anti-PTEN monoclonal antibody; cat. no. BM4114; Wuhan Boster Biological Technology, Ltd., Wuhan, China) overnight at $4^{\circ} \mathrm{C}$ at a 1:500 dilution. Following rinsing with $1 \mathrm{X}$ TBST 5 times for $5 \mathrm{~min}$, the membrane was probed with a secondary antibody (goat anti-mouse IgG; 1:10,000 dilution; cat. no. SA00001-1; ProteinTech Group, Inc., Chicago, IL, USA) for $2 \mathrm{~h}$ at room temperature. Following five washes in TBST, the films of immunoreactive products were scanned using an enhanced chemiluminescence western blot detection system (FluorChem E; ProteinSimple, San Jose, CA, USA) with the ECL Western Blotting Substrate (Thermo Fisher Scientific, Inc.). Quantified data were analyzed using
IPP 6.0 image analysis software (Media Cybernetics, Inc., Rockville, MD, USA). GAPDH (cat. no. BM3876; Wuhan Boster Biological Technology, Ltd.) served as an endogenous reference and antibody was incubated overnight at $4^{\circ} \mathrm{C}$ in a 1:400 dilution.

Luciferase reporter assay. A luciferase reporter assay was used to examine the association between miR-19b-3p and PTEN, following identification of two putative binding sites in the PTEN 3' untranslated region (UTR) using bioinformatics analysis (TargetScan; targetscan.org/vert_72/). PCR primers were designed (forward, 5'-GTACTCGAGAGGATTAATAAA GATGGCACT-3' and reverse, 5'-ACGTCTAGAATCAATA AAGCACATGTAGGAC-3') to amplify wild-type (Wt) and mutant (Mt) PTEN 3'UTR sequences by PCR amplification, and the PUC57-Wt-PTEN 3'UTR and PUC57-Mt-PTEN 3'UTR (Sangon Biotech Co., Ltd., Shanghai, China) were used as the templates for amplification, respectively. A pmirGLO reporter vector was purchased from Promega Corporation, and the fragments that had been amplified beforehand were cloned into the multiple cloning site region of the vector to produce the recombinant vectors pmirGLO-3'UTRPTEN-Wtand pmirGLO-3'UTR PTEN-Mt.

To perform out the luciferase reporter assay, A375 cells were divided into 8 groups and cultured in two 6-well plates. pmirGLO-3'UTR PTEN-Wt or pmirGLO-3'UTR PTEN-Mt vectors $(2 \mu \mathrm{g})$ were co-transfected with miR-control, miR-19b-3p mimic (cat. no. B01001), anti-miR-control or antimiR-19b-3p (cat. no. B03001) into A375 cells as described above. Luciferase activity was then determined at $24 \mathrm{~h}$ posttransfection with a Dual-Luciferase Assay Kit (Promega Corporation).

Statistical analyses. The software SPSS v.21.0 (IBMCorp., Armonk, NY,USA) was used for data analysis. The Student's t-test was used to compare between two groups. One-way analysis of variance was performed to compare data among three or more groups, and further analysis was achieved using Bonferroni or Least Significant Difference test. All values are expressed as the mean \pm standard deviation. $\mathrm{P}<0.05$ was considered to indicate a statistically significant difference.

\section{Results}

Matrine inhibits proliferation and invasiveness, and promotes apoptosis in human A375 and SK-MEL-2 melanoma cell lines. Matrine, one of the main alkaloid components extracted from a traditional Chinese herb, Sophora flavescens Ait, has wide-spread pharmacological effects. The chemical formula of matrine is $\mathrm{C}_{15} \mathrm{H}_{24} \mathrm{~N}_{2} \mathrm{O}$ (Fig. 1A) (24). In the current study, NHEMs, A375 and SK-MEL-2 cells were treated with various concentrations of matrine $(0,250$ and $500 \mu \mathrm{g} / \mathrm{ml})$ for 0-4 days. The CCK- 8 assay was used to compare the proliferation rates of cells at different matrine concentrations. The OD450 values were measured over time and the growth curves were plotted (Fig. 1B). NHEM cells treated with the increasing concentrations of matrine shared similar OD values $(\mathrm{P}>0.05)$; while A375 cells treated with $500 \mu \mathrm{g} / \mathrm{ml}$ matrine exhibited significantly lower OD values than the cells treated with $250 \mu \mathrm{g} / \mathrm{ml}$ matrine and $0 \mu \mathrm{g} / \mathrm{ml}$ matrine $(\mathrm{P}<0.05)$. 
A<smiles>O=C1CCC[C@@H]2[C@H]3CCCN4CCC[C@H]2C4N1C3</smiles>

B

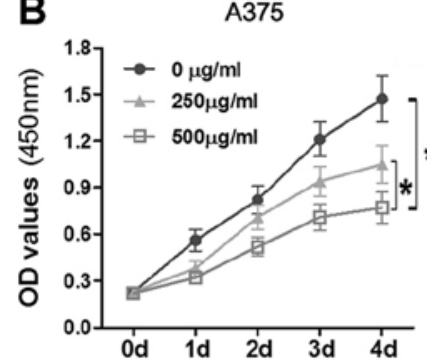

SK-MEL-2

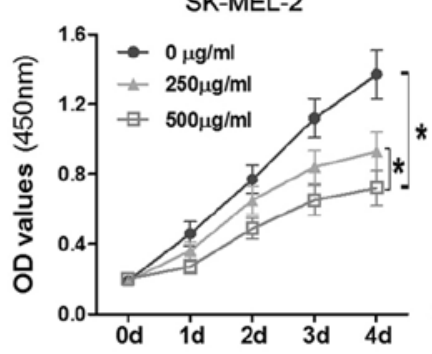

NHEM

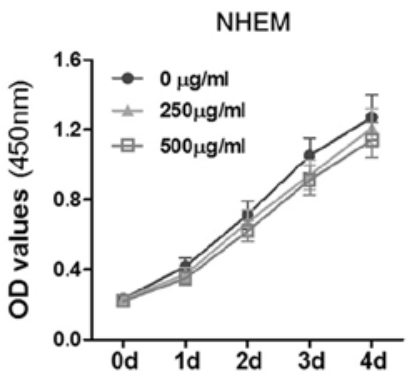

C

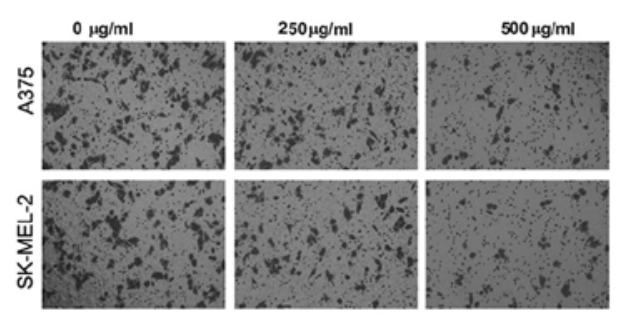

D

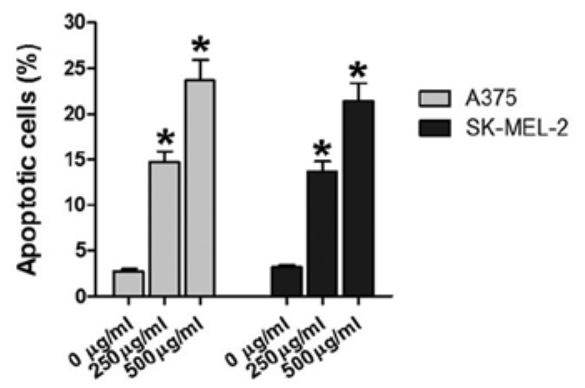

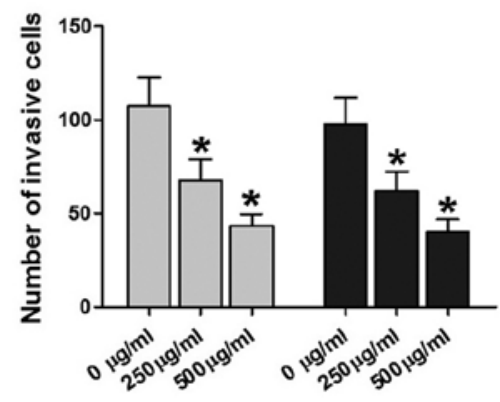

E

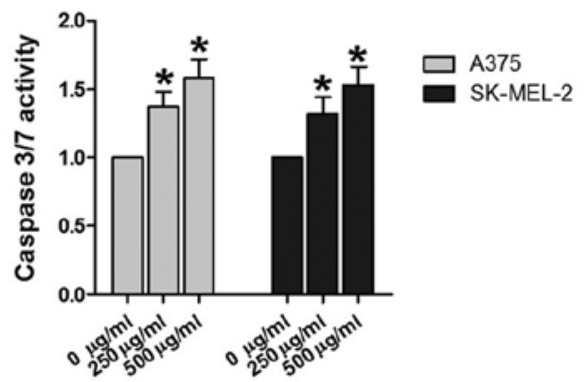

Figure 1. Matrine inhibits proliferation and invasion, and promotes apoptosis of human melanoma cell lines A375 and SK-MEL-2 in vitro. (A) Chemical formula of matrine. (B) Cell proliferation was determined by CCK-8 assays on NHEMs, A375 and SK-MEL-2 cells treated with 0,250 and $500 \mu \mathrm{g} / \mathrm{ml}$ of matrine for 0-4 days. (C) Cell invasion was determined using Transwell assays. (D) Cell apoptosis was analyzed using Annexin/propidium iodide staining and flow cytometry and (E) caspase-3/7 activity detection was performed using A375 and SK-MEL-2 cells treated with 0,250 and $500 \mu$ g/ml of matrine. ${ }^{*} \mathrm{P}<0.05$ vs. $0 \mu \mathrm{g} / \mathrm{ml}$. OD, optical density; NHEM, normal human epidermal melanocytes.

Furthermore, the OD values in the $250 \mu \mathrm{g} / \mathrm{ml}$ group were also significantly lower than those in the $0 \mu \mathrm{g} / \mathrm{ml}$ group $(\mathrm{P}<0.05)$. A similar phenomenon was also observed in the SK-MEL-2 cell line.

Additionally, Transwell assays were performed to determine the invasiveness of following matrine treatment. After incubation for $48 \mathrm{~h}$, the number of invaded A375 cells in the $250 \mu \mathrm{g} / \mathrm{ml}$ group $(62.4 \pm 9.8)$ and $500 \mu \mathrm{g} / \mathrm{ml}$ group $(43.6 \pm 6.1)$ was significantly decreased compared with the control group (105.3 \pm 15.7 ; $\mathrm{P}<0.05$; Fig. 1C). Compared with the cell numbers obtained from CCK-8 assay (Fig. 1B), the relative rate of invaded cells treated in the same condition were relatively decreased, revealing that matrine could inhibit the invasiveness of A375 cells in some degree. Similarly, the number

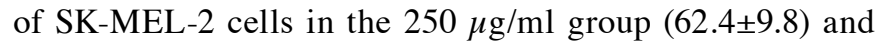
$500 \mu \mathrm{g} / \mathrm{ml}$ group $(60.8 \pm 7.1)$ was also significantly decreased compared with the control group $(95.5 \pm 14.6$; $\mathrm{P}<0.05$; Fig. $1 \mathrm{C})$.

In addition to proliferation and invasion, abnormal apoptosis is another important feature of tumor pathology (25). As demonstrated in Fig. 1D, the flow cytometry analysis revealed that when treated with $250-500 \mu \mathrm{g} / \mathrm{ml}$ matrine, A375 and SK-MEL-2 cells exhibited significantly increased proportions of apoptotic cells $(\mathrm{P}<0.05)$; furthermore, the apoptotic rates were increased with elevated matrine concentration, suggesting that matrine induces cell apoptosis in a dose-dependent manner in vitro. To confirm the results, a caspase- $3 / 7$ assay was also used to detect cell apoptosis. The results demonstrated that caspase- $3 / 7$ activity was significantly increased in the $250-500 \mu \mathrm{g} / \mathrm{ml}$ of matrine treatment groups compared with $0 \mu \mathrm{g} / \mathrm{ml}(\mathrm{P}<0.05$; Fig. $1 \mathrm{E})$, which was consistent with the findings of flow cytometry.

These findings indicated that matrine did not induce marked cytotoxicity in normal cells; and that following treatment with 250 and $500 \mu \mathrm{g} / \mathrm{ml}$ matrine, melanoma cells proliferation and invasion were significantly suppressed, while apoptosis was promoted, and the effects were dose-dependent.

Matrine decreases the expression of miR-19b-3p and increases the expression of PTEN in A375 and SK-MEL-2 cells. The aforementioned experiments demonstrated that matrine inhibited cell proliferation and invasion, and induced cell apoptosis. Subsequently, the effect of matrine on the expression of miR-19b-3p and PTEN was detected using RT-qPCR and western blot assays. miR-19b is part of the miR-17-92 and 

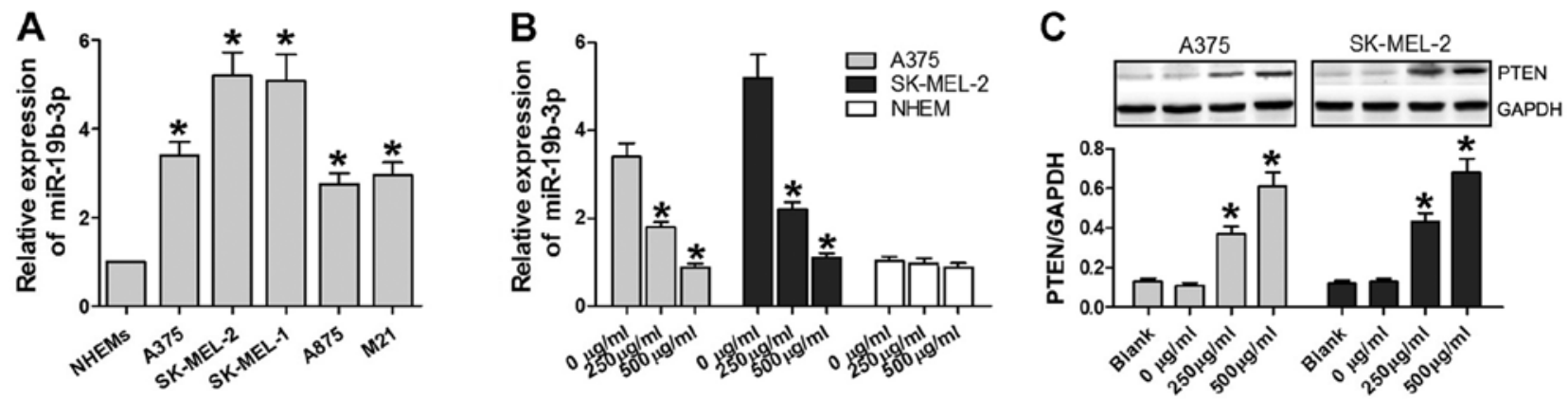

Figure 2. Matrine increases the expression of PTEN, and decreases the expression of miR-19b-3p. (A) miR-19b-3p expression levels as determined by RT-qPCR in NHEMs, A375, SK-MEL-2, SK-MEL-1, A875 and M21 cells. *P<0.05 vs. NHEMs. (B) miR-19b-3p expression levels as detected by RT-qPCR in NHEMs, A375 and SK-MEL-2 cells treated with 0,250 and $500 \mu \mathrm{g} / \mathrm{ml}$ of matrine for $24 \mathrm{~h}$. (C) PTEN protein expression levels as determined by western blot analysis in A375 and SK-MEL-2 cells treated with 0,250 and $500 \mu \mathrm{g} / \mathrm{ml}$ of matrine for $24 \mathrm{~h}$. ${ }^{*} \mathrm{P}<0.05 \mathrm{vs} .0 \mu \mathrm{g} / \mathrm{ml}$ or blank. RT-qPCR, reverse transcription-quantitative polymerase chain reaction; NHEM, normal human epidermal melanocytes; miR, microRNA; PTEN, phosphatase and tensin homolog.
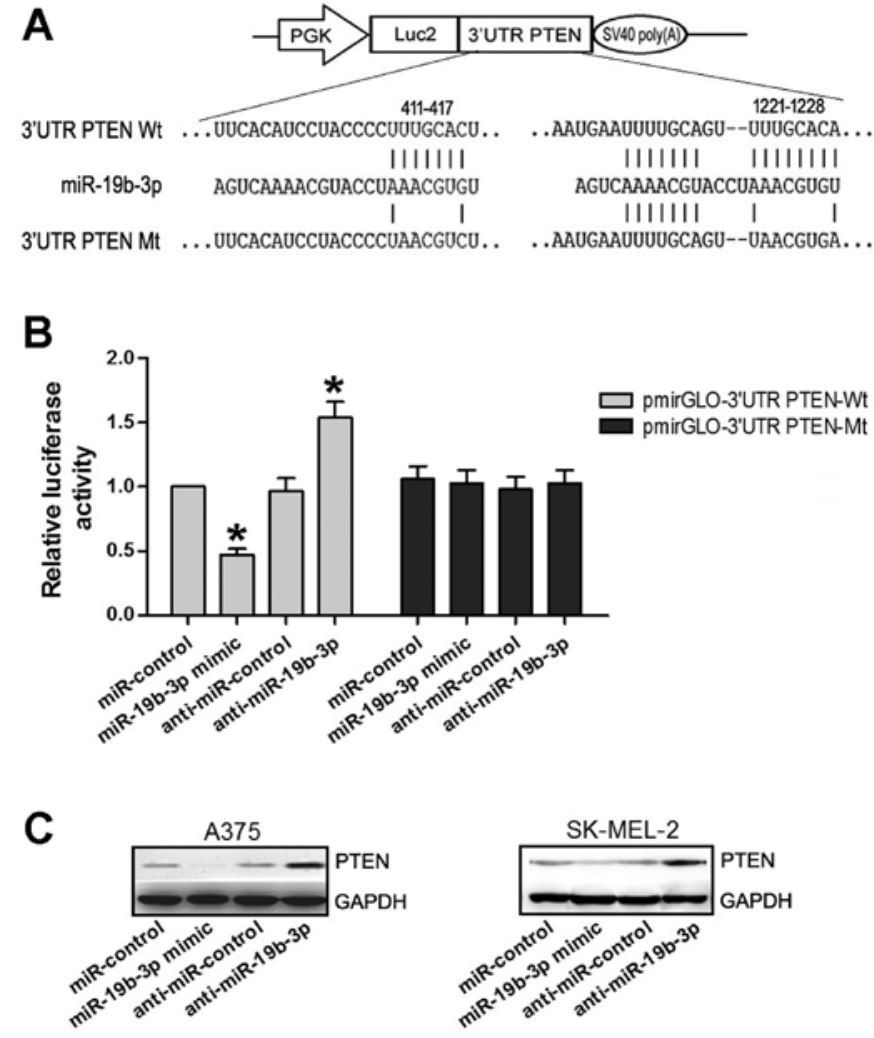

Figure 3. miR-19b-3p targeted PTEN in A375 and SK-MEL-2 cells. (A) Putative binding sites between miR-19b-3p and PTEN 3'UTR identified through bioinformatics analysis. (B) Luciferase activity of Wt and Mt PTEN 3'UTR reporter constructs, relative to miR-control and anti-control groups, in the presence of miR-19b-3p mimic and anti-miR-19b-3p. ${ }^{*} \mathrm{P}<0.05$ vs. respective control. (C) Expression of PTEN as detected through western blot assay in A375 and SK-MEL-2 cells transfected with miR-control, miR-19b-3p mimic, anti-miR-19b-3p or anti-miR-control. PGK, phospho-glycerate kinase promoter; Luc2, firefly luciferase; UTR, untranslated region; PTEN, phosphatase and tensin homolog; Wt, wild-type; miR, microRNA; Mt, mutant.

miR-106-363 clusters. The two miRNA clusters are in the chromosomal region $13 q 31.3$ and $\mathrm{Xq} 26.2$, respectively; with miRNAs at these locations often overexpressed in cancer cells (26-28). In the current study, the expression of miR-19b-3p was measured in five types of melanoma cells, with NHEMs used as a negative control. miR-19b-3p expression in the five melanoma cell lines was upregulated compared with that in the NHEMs $(\mathrm{P}<0.05$; Fig. 2A). Additionally, following treatment with various concentrations of matrine for $48 \mathrm{~h}$, the expression of miR-19b-3p in A375 and SK-MEL-2 cells significantly reduced in the $250-500 \mu \mathrm{g} / \mathrm{ml}$ matrine groups ( $\mathrm{P}<0.05$, Fig. 2B); while there was no significant difference in the expression of miR-19b-3p in NHEMs (P>0.05; Fig. 2B).

PTEN has been reported to be activated by matrine to induce growth inhibition and apoptosis in ${ }^{{ }^{\mathrm{V}} 00 \mathrm{E}} \mathrm{BRAF}$-harboring melanoma cells (29). In the current study, PTEN protein expression was significantly increased in A375 and SK-MEL-2 cells treated with $250 \mu \mathrm{g} / \mathrm{ml}$ matrine groups and $500 \mu \mathrm{g} / \mathrm{ml}$ compared with the blank and $0 \mu \mathrm{g} / \mathrm{ml}$ groups $(\mathrm{P}<0.05$; Fig. $2 \mathrm{C})$. Overall, matrine decreased the expression of miR-19b-3p and increased the expression of PTEN in A375 and SK-MEL-2 cells.

miR-19b-3p targets PTEN in A375 and SK-MEL-2 cells. The findings of the current study indicated that the expression of miR-19b-3p and PTEN was altered in matrine-treated A375 and SK-MEL-2 cells; subsequently, it was aimed to determine whether there is an association between miR-19b-3p and PTEN in melanoma cells. The bioinformatics analysis provided two interactive binding regions between miR-19b-3p and PTEN mRNA (Fig. 3A). Vast amounts of published data indicate that miRNAs can target one or more mRNA species to regulate their expression. To determine whether PTEN expression is regulated by miR-19b-3p, a dual-luciferase reporter assay was performed. During this experiment, A375 cells were divided into eight groups for the different treatments. miR-19b-3p significantly suppressed the luciferase activity in cells transfected with the pmirGLO-3'UTR PTEN-Wt; however, miR-19b-3p failed to inhibit this activity in cells containing the pmirGLO-3'UTR PTEN-Mt (Fig. 3B). Additionally, the cells were also transfected with anti-miR-19b-3p and pmirGLO-3'UTR PTEN-Wt or pmirGLO-3'UTR PTEN-Mt groups, with an anti-miRcontrol group as a negative control. The results revealed that luciferase activity in cells transfected with anti-miR-19b-3p and the pmirGLO-3'UTR PTEN-Wt was at its highest level compared with the other groups $(\mathrm{P}<0.05$; Fig. 3B). Combined with the fact that the protein expression of PTEN was inhibited by $\mathrm{miR}-19 \mathrm{~b}-3 \mathrm{p}$ overexpression and increased by miR-19b-3p downregulation (Fig. 3C), it was concluded that miR-19b-3p targeted PTEN in A375 and SK-MEL-2 cells. 

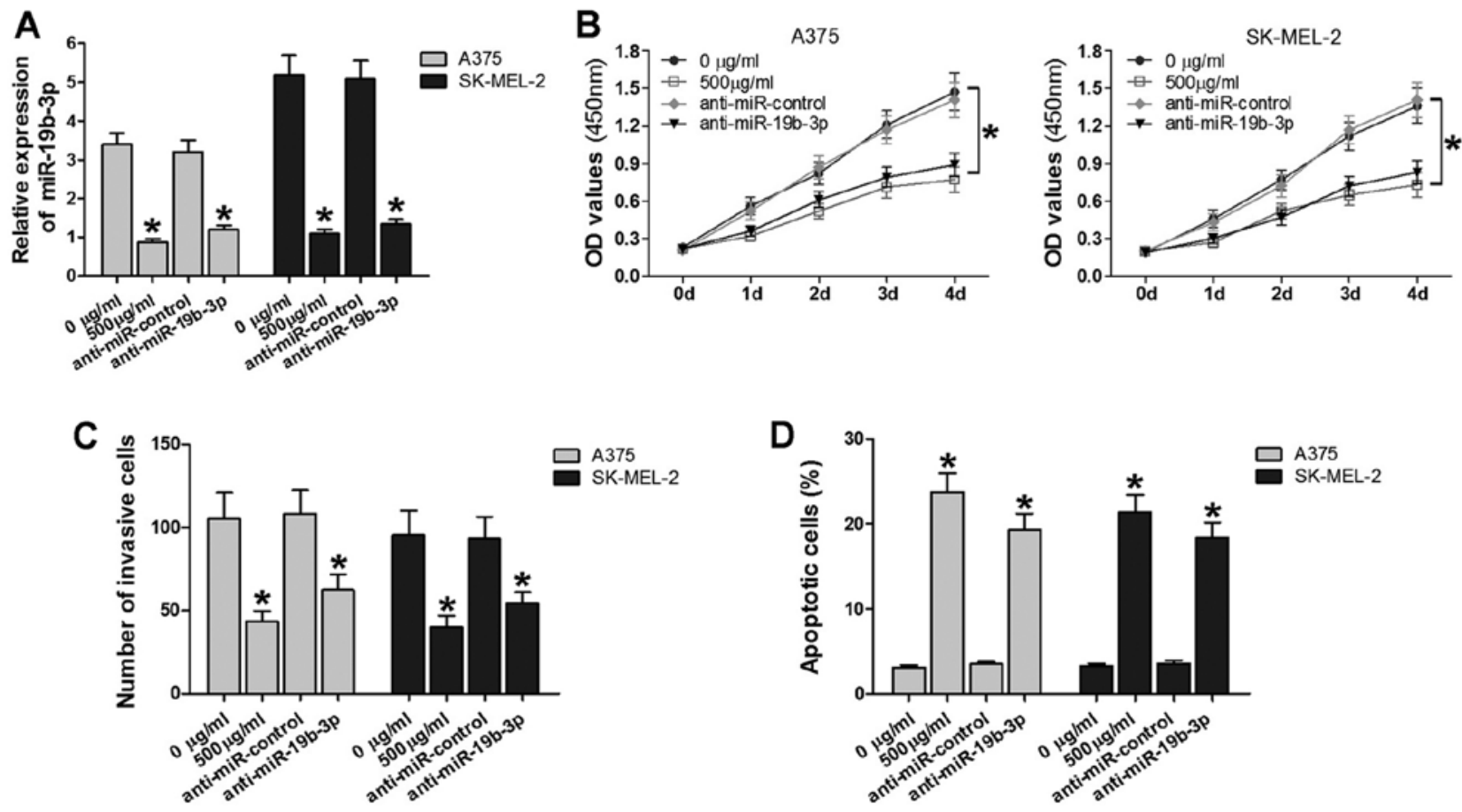

Figure 4. Matrine and downregulated miR-19b-3p are able to suppress cell proliferation and invasiveness, and promote apoptosis in melanoma cells (A) miR-19b-3p expression levels as detected by reverse transcription-quantitative polymerase chain reaction in A375 and SK-MEL-2 cells treated with 0 or $500 \mu \mathrm{g} / \mathrm{ml}$ of matrine, or transfected with anti-miR-19b-3p or anti-miR-control. (B) Cell proliferation was determined by CCK-8 assays in A375 and SK-MEL-2 cells treated with 0 or $500 \mu \mathrm{g} / \mathrm{ml}$ of matrine, or transfected with anti-miR-19b-3p or anti-miR-control. (C) Cell invasion was detected by Transwell assay and (D) cell apoptosis was examined using Annexin V/propidium iodide and flow cytometry in A375 and SK-MEL-2 cells treated with 0 or $500 \mu \mathrm{g} / \mathrm{ml}$ of matrine, or transfected with anti-miR-19b-3p or anti-miR-control. "P<0.05 vs. $0 \mu \mathrm{g} / \mathrm{ml}$ or anti-miR-control. miR, microRNA; OD, optical density.

Matrine shares the similar effects on cell proliferation, invasiveness and apoptosis with miR-19b-3p in A375 and $S K-M E L-2$ cells. miR-19b-3p was verified to be downregulated by matrine. To analyze the biological effects of matrine-mediated regulation of miR-19b-3p in melanoma, the A375 and SK-MEL-2 cell lines were treated with 0 or $500 \mu \mathrm{g} / \mathrm{ml}$ matrine, or transfected with anti-miR-19b-3p or anti-miR-control. As demonstrated in Fig. 4A, the expression of miR-19b-3p was suppressed in the $500 \mu \mathrm{g} / \mathrm{ml}$ matrine groups and antimiR-19b-3p groups. Subsequently, CCK-8, Transwell assay and flow cytometry assays were performed to assess cell proliferation, invasiveness and apoptosis. Cell growth and invasion were significantly inhibited, and the number of apoptotic cells was increased in the $500 \mu \mathrm{g} / \mathrm{ml}$ matrine and anti-miR-19b-3p groups compared with the control groups (Fig. 4B-D). These results indicated that matrine and downregulated miR-19b-3p suppressed cell proliferation and invasiveness, and promoted cell apoptosis. Thus, the two approaches exert similar effects on melanoma cells.

Silencing of PTEN expression reverses the effects of matrine and miR-19b-3p in A375 and SK-MEL-2 cells. It was attempted to determine the advanced molecular mechanisms underlying the effects of matrine and miR-19b-3p. In the current study, si-PTEN was used to silence the expression of PTEN in A375 and SK-MEL-2 cells. PTEN expression was then evaluated by western blot analysis, which demonstrated that PTEN was markedly increased following transfection with anti-miR-19b-3p or treatment with $500 \mu \mathrm{g} / \mathrm{ml}$ matrine, and decreased by transfection with si-PTEN. Additionally, PTEN was reduced in cells co-transfected with si-PTEN and anti-miR-19b-3p, and in cells treated with matrine and si-PTEN, compared with those in the anti-miR-19b-3p and matrine treatment groups, respectively $(\mathrm{P}<0.05$; Fig. 5A). Transwell assay results demonstrated that compared with cells transfected with anti-miR-19b-3p or treated with $500 \mu \mathrm{g} / \mathrm{ml}$ matrine alone, the number of invasive cells was significantly increased in the cells transfected with si-PTEN, co-transfected with si-PTEN and anti-miR-19b-3p, or simultaneously treated with matrine and si-PTEN (P<0.05; Fig. 5B). Flow cytometry revealed that compared with cells transfected with anti-miR-19b-3p or treated with $500 \mu \mathrm{g} / \mathrm{ml}$ matrine alone, the number of apoptotic cells was significantly reduced in cells transfected with si-PTEN, co-transfected with si-PTEN and anti-miR-19b-3p, or simultaneously treated with matrine and si-PTEN ( $\mathrm{P}<0.05$; Fig. 5C). In these experiments, a scramble si-PTEN was used; when compared with the blank group, the scramble si-PTEN group shared a similar effect. Thus, only the blank group is shown as a negative control in Fig. 5. These results further suggested that silencing of PTEN expression reverses the effects of matrine and miR-19b-3p downregulation in A375 and SK-MEL-2 cells.

\section{Discussion}

Due to its rapidly increasing incidence rate and poor prognosis, melanoma is one of the most lethal skin diseases. Several high-throughput studies have indicated that matrine is associated with antitumor activity in melanoma. For example, matrine has a significant inhibitory effect on the adhesion and invasiveness of malignant human A375 melanoma cell line by 
A

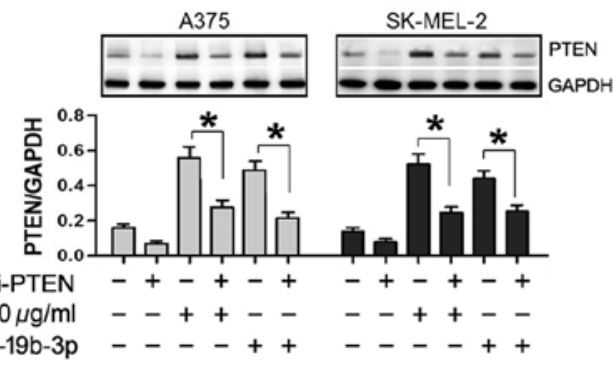

B

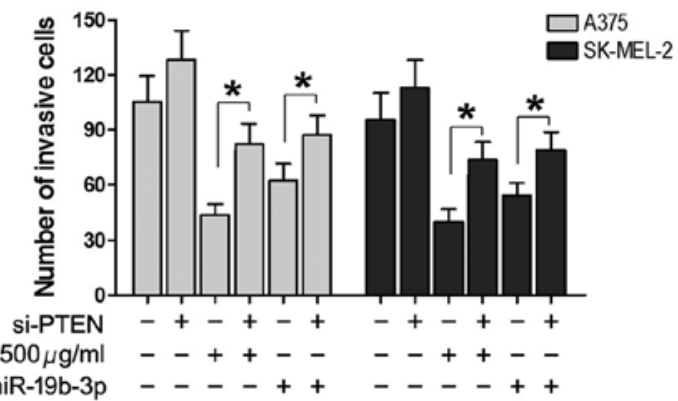

C

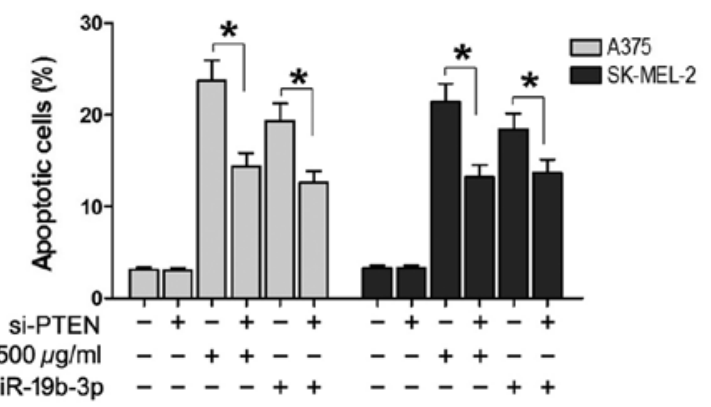

Figure 5. Silencing of PTEN expression reverses the effects of matrine and miR-19b-3p in A375 and SK-MEL-2 cells. (A) PTEN expression was evaluated by western blot assay for each group of transfected A375 and SK-MEL-2 cells. (B) Cell invasion capacities determined by Transwell assay. (C) Cell apoptosis was examined using Annexin V/propidium iodide and flow cytometry. ${ }^{*} \mathrm{P}<0.05$. PTEN, phosphatase and tensin homolog; si, small interfering RNA; miR, microRNA.

downregulating the expression of heparanase mRNA (30); and matrine inhibits the invasiveness and metastasis of A375 cells in vitro (31). However, the antitumor potential and underlying mechanisms of matrine remain largely unknown.

The mechanisms may be associated with the inhibition of cellular proliferation, induction of apoptosis and autophagy, arrest of cell cycle, inhibition of angiogenesis and downregulation of target mRNA and protein expression. As reported, matrine induces cell cycle arrest and apoptosis with recovery of the expression of miR-126 in the A549 non-small cell lung cancer cell line (32). Matrine inhibited the invasion and metastasis of lung cancer cells by elevating expression of miR-133a, which further suppressed activation of epidermal growth factor receptor/protein kinase B (Akt)/matrix metalloproteinase-9 pathway (33). Furthermore, matrine can inhibit breast cancer growth via an miR-21/PTEN/Akt pathway in MCF-7 cells (34). These studies reinforce the notion that miRNAs can act as mediators of the therapeutic efficacy of natural medicines.

The current study initially confirmed the effects of matrine on cell proliferation, invasion and apoptosis in A375 and SK-MEL-2 melanoma cell lines. The results of CCK-8 assay demonstrated that the number of A375 and SK-MEL-2 cells was significantly decreased following treatment with matrine. Cell apoptosis or other factors all influence the number of living cells. In the current study, in the different groups of A 375 and SK-MEL-2 cells treated with various concentrations of matrine for $48 \mathrm{~h}$, live cells in the $250 \mu \mathrm{g} / \mathrm{ml}$ group accounted for $\sim 75 \%$ of the $0 \mu \mathrm{g} / \mathrm{ml}$ group, live cells in $500 \mu \mathrm{g} / \mathrm{ml}$ group accounted for $\sim 60 \%$ of the $0 \mu \mathrm{g} / \mathrm{ml}$ group. The results of transwell assay demonstrated that in the different groups of A375 and SK-MEL-2 cells treated with various concentrations of matrine for $48 \mathrm{~h}$, invaded cells in $250 \mu \mathrm{g} / \mathrm{ml}$ group accounted for $\sim 60 \%$ of the $0 \mu \mathrm{g} / \mathrm{ml}$ group, which was lower than the $75 \%$ observed in the CCK- 8 assay, and invaded cells in the $500 \mu \mathrm{g} / \mathrm{ml}$ group accounted for $\sim 40 \%$ of the $0 \mu \mathrm{g} / \mathrm{ml}$ group, which was lower than the $60 \%$ observed in the CCK-8 assay. The results above verified that the decrease of cells in the invasion assay was not caused solely by reduced cell viability, but also caused by the reduced invasion capacity. Matrine has an inhibitory effect on cell invasion to a certain degree in melanoma cells. It is concluded that matrine inhibited the proliferation and invasiveness of A375 and SK-MEL-2 cells, and induced cell apoptosis with dose-dependence in vitro. The concentrations used in the current study were 0,250 and $500 \mu \mathrm{g} / \mathrm{ml}$, which were similar to the concentration used in an in vivo experiment by Liou et al (35) and far beyond the effectual dose in normal cells in vitro (29). Next, based on the fact that miR-19b was found to be overexpressed through our previous miRNA microarray (18), miR-19b was verified to be higher in five types of melanoma cells compared with in NHEMs $(36,37)$. Moreover, when treated with matrine, miR-19b expression was significantly downregulated in A375 and SK-MEL-2 cells, revealing that matrine could inhibit miR-19b expression in vitro. To explore the advanced molecular mechanisms, bioinformatics analysis was performed, which indicated the presence of two interactive binding regions between miR-19b-3p and PTEN mRNA.

The tumor inhibitor gene PTEN is a $47-\mathrm{kDa}$ protein first identified as a candidate tumor suppressor gene in $1997(38,39)$. Thus far, vast amounts of data published indicate that PTEN has antitumor activity. Cordes et al (40) reported that PTEN is associated with an aggressive tumor phenotype and with unfavorable outcome in early bladder cancer. Additionally, a high level of PTEN expression has been associated with low-grade liver metastasis and satisfactory patient survival in pancreatic cancer (41). PTEN was also reported to be activated by matrine to induce growth inhibition and apoptosis in ${ }^{{ }^{6} 00 \mathrm{E}} \mathrm{BRAF}$-harboring melanoma cells (29). In the current study, treatment with matrine increased the PTEN protein expression in A375 and SK-MEL-2 cells in vitro. Based on the results of bioinformatics analysis, 
Table I. Association between PTEN gene and miR-19 in different type of cancer.

\begin{tabular}{|c|c|c|c|c|c|}
\hline Author, year & Cancer type & $\begin{array}{c}\text { miR-19 } \\
\text { expression }\end{array}$ & $\begin{array}{c}\text { PTEN } \\
\text { expression }\end{array}$ & Function & Ref. \\
\hline Liu et al, 2017 & Wilms' tumor & Up & Down & $\begin{array}{l}\text { Inhibition of miR-19b suppresses the progression } \\
\text { of Wilms' tumor by modulating } \\
\text { the PTEN/PI3K/Akt signaling pathway }\end{array}$ & $(42)$ \\
\hline Li et al, 2017 & Breast cancer & Up & Down & $\begin{array}{l}\text { Enhanced PTEN pseudogene } 1 \text { could inhibit breast cancer } \\
\text { cell growth, metastasis and tumorigenicity } \\
\text { by inhibiting miR-19b and facilitating PTEN in breast cancer }\end{array}$ & (43) \\
\hline Chen et al, 2016 & $\begin{array}{l}\text { Human } \\
\text { neuroblastoma }\end{array}$ & $\begin{array}{l}\text { No } \\
\text { description }\end{array}$ & $\begin{array}{l}\text { No } \\
\text { description }\end{array}$ & $\begin{array}{l}\text { Antagomir of miR-19b decreases cell viability } \\
\text { and phospho-Akt expression and increases } \\
\text { PTEN expression in neuroblastoma cells }\end{array}$ & (44) \\
\hline Li et al, 2015 & Lung cancer & $\begin{array}{l}\text { No } \\
\text { description }\end{array}$ & $\begin{array}{l}\text { No } \\
\text { description }\end{array}$ & $\begin{array}{l}\text { PTEN is involved in miR-19-induced } \\
\text { epithelial-mesenchymal transition, migration } \\
\text { and invasion in lung cancer cells }\end{array}$ & $(45)$ \\
\hline Li et al, 2014 & Breast cancer & Up & Down & $\begin{array}{l}\text { Curcumin modulates miR-19/PTEN/Akt/p53 axis } \\
\text { to exhibit its protective effects against } \\
\text { bisphenol A-associated breast cancer promotion }\end{array}$ & (46) \\
\hline Tian et al, 2013 & Gliomas & Up & Down & $\begin{array}{l}\text { miR-19a and miR-19b may have an oncogenic role } \\
\text { in gliomagenesis at least partially } \\
\text { via the negative regulation of PTEN }\end{array}$ & $(47)$ \\
\hline Jia et al, 2013 & $\begin{array}{l}\text { Prostate } \\
\text { cancer }\end{array}$ & Up & Down & $\begin{array}{l}\text { miR-19b could promote prostate cancer cell proliferation } \\
\text { by coregulating the expression of PTEN, } \\
\text { PI3K/Akt pathway and cyclin D1 in vitro }\end{array}$ & $(48)$ \\
\hline
\end{tabular}

PTEN, phosphatase and tensin homolog; miR, microRNA; PI3K, phosphatidylinositol-3 kinase; Akt, protein kinase B.

a dual-luciferase reporter assay was performed to explore the association between miR-19b-3p and PTEN. The results demonstrated that PTEN was a target of miR-19b-3p. A subsequent western blot assay demonstrated that miR-19b-3p regulated the protein level of PTEN in A375 and SK-MEL-2 cells. Numerous studies (42-48) have also reported that miR-19 (miR-19a or miR-19b) regulates the expression of PTEN, and as a result modulates cancer biology, in processes including cancer cell apoptosis, proliferation, invasion, metastasis and cell cycling (Table I). The findings of the current study demonstrated that miR-19b targets PTEN in melanoma cells; matrine also decreased the expression of miR-19b-3p and increased the expression of PTEN in A375 and SK-MEL-2 cells, while the association between matrine, miR-19b and PTEN in melanoma remained unclear. To address the biological functions of matrine and miR-19b-3p, the effects of the two components on cell proliferation, invasion and apoptosis were compared. Matrine and anit-miR-19b-3p induced similar effects in the melanoma cell lines. Furthermore, when the expression of PTEN was silenced, the inhibitory effects on proliferation and invasion and the promotion of apoptosis by matrine or downregulated miR-19b-3p were reversed.

In summary, the findings of the current study suggested that matrine suppresses cell proliferation, invasion and induce cell apoptosis partially through miR-19b-3p targeting PTEN, thus enriching the understanding of the molecular mechanisms of matrine in reducing melanoma progression and metastasis. However, the current study did not explore whether overexpression of miR-19b-3p inhibited the effects of matrine, which requires future investigation. Additionally, determining whether matrine has potential for use in vivo or in a clinical setting will require thorough investigation. Various approaches, including the use of liposomes, nanoparticles, micelles and phospholipid complexes, may improve the pharmacokinetic profile of matrine, which may promote the future application of matrine in the clinic.

\section{Acknowledgements}

Thanks are given to the People's Hospital of Jiaozuo City (Jiaozuo, China) for providing the experimental platform.

\section{Funding}

No funding was received.

\section{Availability of data and materials}

The datasets used and/or analyzed during the current study are available from the corresponding author on reasonable request.

\section{Authors' contributions}

YPW and LDZ designed the study and performed part of the statistical analysis of data. YPW, XHW, GL and JFZ performed 
the cell-based experiments including CCK-8, Transwell, flow cytometry, caspase-3/7 activity detection and luciferase reporter assay. YXY and JZ were responsible for consulting the literature, involved in experimental design, bioinformatics analysis, writing the manuscript and participating in revising it critically for the comments. XLS and ZGL performed the RT-qPCR and western blot assay and performed the statistical analysis. All authors have approved the final manuscript.

\section{Ethics approval and consent to participate}

Not applicable.

\section{Consent for publication}

Not applicable.

\section{Competing interests}

The authors declare that they have no competing interests.

\section{Reference}

1. Flaherty KT, Robert C, Hersey P, Nathan P, Garbe C, Milhem M, Demidov LV, Hassel JC, Rutkowski P, Mohr P, et al; METRIC Study Group: Improved survival with MEK inhibition in BRAF-mutated melanoma. N Engl J Med 367: 107-114, 2012.

2. Guo J, Si L, Kong Y, Flaherty KT, Xu X, Zhu Y, Corless CL, Li L, Li H, Sheng X, et al: Phase II, open-label, single-arm trial of imatinib mesylate in patients with metastatic melanoma harboring c-Kit mutation or amplification. J Clin Oncol 29: 2904-2909, 2011.

3. Hauschild A, Grob JJ, Demidov LV, Jouary T, Gutzmer R, Millward M, Rutkowski P, Blank CU, Miller WH Jr, Kaempgen E, et al: Dabrafenib in BRAF-mutated metastatic melanoma: A multicentre, open-label, phase 3 randomised controlled trial. Lancet 380: 358-365, 2012.

4. Hodi FS, O'Day SJ, McDermott DF, Weber RW, Sosman JA, Haanen JB, Gonzalez R, Robert C, Schadendorf D, Hassel JC, et al: Improved survival with ipilimumab in patients with metastatic melanoma. N Engl J Med 363: 711-723, 2010.

5. Lanoy E: Epidemiology, risk factor and screening for melanoma and other skin cancers. Rev Prat 64: 31-36, 2014 (In French).

6. Haiducu ML, Hinek A, Astanehe A, Lee TK and Kalia S: Extracutaneous melanoma epidemiology in British Columbia. Melanoma Res 24: 377-380, 2014.

7. Fu Q, Fang Q, Feng B, Sun S, Du W, Amut E, Xiao A and Chang C: Matrine-imprinted monolithic stationary phase for extraction and purification of matrine from Sophorae flaves centis Ait. J Chromatogr B Analyt Technol Biomed Life Sci 879: 894-900, 2011

8. Guo Z, Zhang L, Song C and Zhang X: Molecularly imprinted solid-phase extraction of matrine from radix Sophorae tonkinensis. Analyst (Lond) 136: 3016-3022, 2011.

9. Kucukboyaci N,Ozkan S, Adiguzel Nand TosunF: Characterisation and antimicrobial activity of Sophora alopecuroides L. var. alopecuroides alkaloid extracts. Turk J Biol 35: 379-385, 2011.

10. Zhang JP, Zhang M, Zhou JP, Liu FT, Zhou B, Xie WF and Guo C: Antifibrotic effects of matrine on in vitro and in vivo models of liver fibrosis in rats. Acta Pharmacol Sin 22: 183-186, 2001.

11. Zhang B, Liu ZY, Li YY, Luo Y, Liu ML, Dong HY, Wang YX, Liu Y, Zhao PT, Jin FG, et al: Antiinflammatory effects of matrine in LPS-induced acute lung injury in mice. Eur J Pharm Sci 44: 573-579, 2011

12. Chang C, Liu SP, Fang CH, He RS, Wang Z, Zhu YQ and Jiang SW: Effects of matrine on the proliferation of HT29 human colon cancer cells and its antitumor mechanism. Oncol Lett 6 : 699-704, 2013

13. Liu YQ, Li Y, Qin J, Wang Q, She YL, Luo YL, He JX, Li JY and Xie XD: Matrine reduces proliferation of human lung cancer cells by inducing apoptosis and changing miRNA expression profiles. Asian Pac J Cancer Prev 15: 2169-2177, 2014.
14. Shao H, Yang B, Hu R and Wang Y: Matrine effectively inhibits the proliferation of breast cancer cells through a mechanism related to the NF- $\mathrm{kB}$ signaling pathway. Oncol Lett 6: 517-520, 2013.

15. Zhang P, Wang Z, Chong T and Ji Z: Matrine inhibits proliferation and induces apoptosis of the androgen independent prostate cancer cell line PC-3. Mol Med Rep 5: 783-787, 2012.

16. Li Y, Zhang ZN, Zhao HM, Tong ZC, Yang J, Wang $\mathrm{H}$ and Liang XJ: Matrine inhibits the invasive properties of human osteosarcoma cells by downregulating the ERK-NF- $\kappa$ B pathway. Anticancer Drugs 25: 1035-1043, 2014.

17. Liu Y, Xu Y, Ji W, Li X, Sun B, Gao Q and Su C: Antitumor activities of matrine and oxymatrine: Literature review. Tumour Biol 35: 5111-5119, 2014.

18. Li H, Xie S, Liu X, Wu H, Lin X, Gu J, Wang H and Duan Y: Matrine alters microRNA expression profiles in SGC-7901 human gastric cancer cells. Oncol Rep 32: 2118-2126, 2014.

19. Zhao L, Zhao Y, He Y and Mao Y: miR-19b promotes breast cancer metastasis through targeting MYLIP and its related cell adhesion molecules. Oncotarget 8: 64330-64343, 2017.

20. Jiang T, Ye L, Han Z, Liu Y, Yang Y, Peng Z and Fan J: miR19b-3p promotes colon cancer proliferation and oxaliplatin-based chemoresistance by targeting SMAD4: Validation by bioinformatics and experimental analyses. J Exp Clin Cancer Res 36: $131,2017$.

21. Ohira T, Naohiro S, Nakayama Y, Osaki M, Okada F, Oshimura M and Kugoh H: miR-19b regulates hTERT mRNA expression through targeting PITX1 mRNA in melanoma cells. Sci Rep 5: $8201,2015$.

22. Chen L, Chen Q, Deng G, Kuang S, Lian J, Wang M and Zhu H: AMPK activation by GSK621 inhibits human melanoma cells in vitro and in vivo. Biochem Biophys Res Commun 480: 515-521, 2016.

23. Wilking MJ, Singh C, Nihal M, Zhong W and Ahmad N: SIRT1 deacetylase is overexpressed in human melanoma and its small molecule inhibition imparts anti-proliferative response via p53 activation. Arch Biochem Biophys 563: 94-100, 2014.

24. Lai JP, He XW, Jiang Y and Chen F: Preparative separation and determination of matrine from the Chinese medicinal plant Sophora flavescens Ait by molecularly imprinted solid-phase extraction. Anal Bioanal Chem 375: 264-269, 2003.

25. Shimizu S: Development of anticancer drugs mediated by apoptosis and autophagy. Nihon Rinsho 73: 1302-1307, 2015.

26. Volinia S, Calin GA, Liu CG, Ambs S, Cimmino A, Petrocca F, Visone R, Iorio M, Roldo C, Ferracin M, et al: A microRNA expression signature of human solid tumors defines cancer gene targets. Proc Natl Acad Sci USA 103: 2257-2261, 2006.

27. He L, Thomson JM, Hemann MT, Hernando-Monge E, Mu D, Goodson S, Powers S, Cordon-Cardo C, Lowe SW, Hannon GJ, et al: A microRNA polycistron as a potential human oncogene. Nature 435: 828-833, 2005.

28. Ota A, Tagawa H, Karnan S, Tsuzuki S, Karpas A, Kira S, Yoshida $\mathrm{Y}$ and Seto M: Identification and characterization of a novel gene, C13orf25, as a target for 13q31-q32 amplification in malignant lymphoma. Cancer Res 64: 3087-3095, 2004.

29. Jin H, Sun Y, Wang S and Cheng X: Matrine activates PTEN to induce growth inhibition and apoptosis in ${ }^{\mathrm{V} 600 \mathrm{E}} \mathrm{BRAF}$ harboring melanoma cells. Int J Mol Sci 14: 16040-16057, 2013.

30. Liu XY, Fang H, Yang ZG, Teng LS, Ruan LM, Fang DR and Jiang XL: Inhibition of invasiveness and expression of heparanase-mRNA in human malignant melanoma cell line A375 by matrine. Zhong Yao Cai 29: 253-256, 2006.

31. Liu XY, Fang H, Yang ZG, Wang XY, Ruan LM, Fang DR, Ding YG, Wang YN, Zhang Y, Jiang XL, et al: Matrine inhibits invasiveness and metastasis of human malignant melanoma cell line A375 in vitro. Int J Dermatol 47: 448-456, 2008.

32. An Q, Han C, Zhou Y, Li F, Li D, Zhang X, Yu Z, Duan Z and Kan Q: Matrine induces cell cycle arrest and apoptosis with recovery of the expression of miR-126 in the A549 non-small cell lung cancer cell line. Mol Med Rep 14: 4042-4048, 2016.

33. Liao H, Zhao X, Qu J, Zhang J and Cai H: Matrine suppresses invasion and metastasis of NCI-H1299 cells by enhancing microRNA-133a expression. Int J Clin Exp Med 8: 10714-10722, 2015.

34. Li LQ, Li XL, Wang L, et al: Matrine inhibits breast cancer growth via miR-21/PTEN/Akt pathway in MCF-7 cells. Cell Physiol Biochem 30: 631-641, 2012.

35. Liou CJ, Lai YR, Chen YL, Chang YH, Li ZY and Huang WC: Matrine attenuates COX-2 and ICAM-1 expressions in human lung epithelial cells and prevents acute lung injury in LPS-induced mice. Mediators Inflamm 2016: 3630485, 2016 
36. Bhatt KV, Spofford LS, Aram G, McMullen M, Pumiglia K and Aplin AE: Adhesion control of cyclin D1 and p27Kip1 levels is deregulated in melanoma cells through BRAF-MEK-ERK signaling. Oncogene 24: 3459-3471, 2005.

37. Satoh R, Hagihara K, Matsuura K, Manse Y, Kita A, Kunoh T, Masuko T, Moriyama M, Moriyama H, Tanabe G, et al: Identification of ACA-28, a 1'-acetoxychavicol acetate analogue compound, as a novel modulator of ERK MAPK signaling, which preferentially kills human melanoma cells. Genes Cells 22 608-618, 2017.

38. Li J, Yen C, Liaw D, Podsypanina K, Bose S, Wang SI, Puc J, Miliaresis C, Rodgers L, McCombie R, et al: PTEN, a putative protein tyrosine phosphatase gene mutated in human brain, breast, and prostate cancer. Science 275: 1943-1947, 1997.

39. Steck PA, Pershouse MA, Jasser SA, Yung WK, Lin H, Ligon AH, Langford LA, Baumgard ML, Hattier T, Davis T, et al: Identification of a candidate tumour suppressor gene, MMAC1 at chromosome 10q23.3 that is mutated in multiple advanced cancers. Nat Genet 15: 356-362, 1997.

40. Cordes I, Kluth M, Zygis D, Rink M, Chun F, Eichelberg C, Dahlem R, Fisch M, Höppner W, Wagner W, et al: PTEN deletions are related to disease progression and unfavourable prognosis in early bladder cancer. Histopathology 63: 670-677, 2013.

41. Feng C, Yao R, Huang F, Liu X and Nie W: High level of PTEN expression is associated with low-grade liver metastasis and satisfactory patient survival in pancreatic cancer. Arch Med Res 42: 584-588, 2011.
42. Liu GL, Yang HJ, Liu B and Liu T: Effects of microRNA-19b on the proliferation, apoptosis, and migration of Wilms' tumor cells via the PTEN/PI3K/AKT signaling pathway. J Cell Biochem 118: 3424-3434, 2017.

43. Li RK, Gao J, Guo LH, Huang GQ and Luo WH: PTENP1 acts as a ceRNA to regulate PTEN by sponging miR-19b and explores the biological role of PTENP1 in breast cancer. Cancer Gene Ther 24: 309-315, 2017.

44. Chen Y, Tsai YH, Tseng BJ, Pan HY and Tseng SH: Suppression of miR-19b enhanced the cytotoxic effects of mTOR inhibitors in human neuroblastoma cells. J Pediatr Surg 51: 1818-1825, 2016.

45. Li J, Yang S, Yan W, Yang J, Qin YJ, Lin XL, Xie RY, Wang SC, Jin W, Gao F, et al: MicroRNA-19 triggers epithelial-mesenchymal transition of lung cancer cells accompanied by growth inhibition. Lab Invest 95: 1056-1070, 2015.

46. Li X, Xie W, Xie C, Huang C, Zhu J, Liang Z, Deng F, Zhu M, Zhu W, Wu R, et al: Curcumin modulates miR-19/PTEN/AKT/ p53 axis to suppress bisphenol A-induced MCF-7 breast cancer cell proliferation. Phytother Res 28: 1553-1560, 2014.

47. Tian L, Fang YX, Xue JL and Chen JZ: Four microRNAs promote prostate cell proliferation with regulation of PTEN and its downstream signals in vitro. PLoS One 8: e75885, 2013.

48. Jia Z, Wang K, Zhang A, Wang G, Kang C, Han L and Pu P: miR-19a and miR-19b overexpression in gliomas. Pathol Oncol Res 19: 847-853, 2013 